\title{
Identificación de Peronospora sparsa y evaluación del contenido de fenoles en frutos de mora de castilla afectados por este microorganismo
}

\author{
Nathalia Cardona Hurtado ${ }^{*} \mathbb{0}$, Gloria Edith Guerrero Álvarez', Ana María López Gutiérrez $z^{2}$
}

10.1590/0034-737X201966010002

\section{RESUMEN}

La enfermedad mildeo velloso en mora de castilla es causada por patógenos pertenecientes al género Peronospora, el cual genera graves pérdidas en periodos cortos y afecta principalmente hojas, tallos y frutos; además, la presencia de agentes infecciosos ocasiona estrés en las plantas, activando la síntesis de metabolitos secundarios como mecanismo de defensa. El objetivo del estudio fue establecer la identidad taxonómica de la especie Peronospora causante de la enfermedad mildeo velloso en mora de castilla (Rubus glaucus Benth) cultivados en la región andina de Colombia y determinar su efecto en el contenido de fenoles totales en los frutos. La investigación se llevó a cabo en los municipios de Santuario y Santa Rosa de Cabal, departamento de Risaralda, Colombia, entre los meses de febrero y mayo del año 2017. Se seleccionaron y analizaron dos cultivos por cada municipio. Se realizó la identificación taxonómica del hongo Peronospora sp., mediante la amplificación por reacción en cadena de la polimerasa (PCR) y la evaluación del contenido de fenoles totales, por el método de Folin-Ciocalteu. La especie Peronospora sparsa fue la causante de la enfermedad en mora de castilla en el departamento de Risaralda. Además, se encontraron diferencias significativas en el contenido de fenoles totales en el material evaluado ( $\mathrm{p}<0.05$ ). La presencia del hongo $P$. sparsa en frutos de $R$. glaucus produjo un incremento en el contenido de compuestos fenólicos, pasando de $7.75 \pm 0.71 \mathrm{mg} \mathrm{g}^{-1}$ de AGE con base húmeda en los frutos sanos, a un valor de $14.70 \pm 1.11 \mathrm{mg} \mathrm{g}^{-1}$ de AGE con base húmeda para los frutos afectados.

Palabras-clave: determinación de especies; metabolitos secundarios; mildeo velloso; productividad agrícola.

\section{RESUMO}

\section{Identificação de Peronospora sparsa e avaliação do conteúdo de fenóis em frutos de "mora de castilla" afetados por esse microrganismo}

O míldio é uma doença da amora (mora de castilla) causada por patógenos do género Peronospora. Ela gera grandes perdas no cultivo em curtos períodos, afetando principalmente folhas, troncos e frutos. Adicionalmente, a presença de agentes infecciosos provoca estresse da planta ativando a síntese de metabolitos secundários como mecanismo de defesa. O objetivo do presente estudo foi estabelecer a identidade taxonômica da espécie Peronospora que causa a doença "mildeo velloso" em amora (Rubus glaucus Benth) cultivada na região andina Colombiana e determinar o seu efeito no conteúdo de fenóis totais em fruto. A pesquisa foi desenvolvida nos municípios de Santuario e Santa Rosa de Cabal no departamento de Risaralda (Colômbia) entre fevereiro e maio do 2017. Foram selecionados e avaliados dois cultivares em cada município. A identificação taxonômica do fungo Peronospora sp., foi completada mediante a Reação em Cadeia da Polimerase (PCR) e a avaliação do conteúdo total de fenóis pelo método de Folin-Ciocalteu. A espécie Peronospora sparsa foi a responsável pela doença citada em amora no departamento de Risaralda. Além disso, foram encontradas diferenças significativas no teor de fenóis totais no material avaliado $(p<0.05)$. A presença do fungo $P$. sparsa em frutos de $R$. glaucus, resultou em acréscimo do teor de compostos fenólicos de $7.75 \pm 0.71 \mathrm{mg}$ de equivalente de ácido gálico $\mathrm{g}^{-1}$ para $14.70 \pm 1.11 \mathrm{mg}$ de equivalente de ácido gálico $\mathrm{g}^{-1}$ de fruto doente.

Palavras-chave: Determinação de espécies, metabólitos secundários, míldio, produtividade agrícola.

\footnotetext{
Presentado en 02/04/2018 y aceptado en 30/01/2019

${ }^{1}$ Universidad Tecnológica de Pereira, Facultad de Tecnología, Escuela de Química, Grupo de Investigación Oleoquímica, Pereira, Risaralda, Colombia. nathacardona@utp.edu.co; gguerrero@utp.edu.co

${ }^{2}$ Universidad Tecnológica de Pereira, Facultad de Ciencias Ambientales, Grupo de Investigación Biodiversidad y Biotecnología, Pereira, Risaralda, Colombia. alopez@utp.edu.co *autor de correspondencia: nathacardona @utp.edu.co
} 


\section{INTRODUCCIÓN}

La mora de castilla (Rubus glaucus Benth) se cultiva en diecinueve departamentos de Colombia y es considerada como una fruta competitiva, ya que su producción nacional es permanente. Esta planta es de amplio consumo, tiene aplicaciones en la agroindustria, posee potencial de exportación y es de gran importancia económica. Sus frutos se consumen frescos y también son utilizados a nivel industrial para la obtención de pulpas, mermeladas y yogures. Sin embargo, los cultivos se exponen de manera importante a enfermedades como el mildeo velloso, asociada al hongo Peronospora sp. Dicha patología se presenta en hojas, ramas y frutos de huéspedes susceptibles, formando un "bloom downy", que consiste en esporangióforos y esporangios en la superficie de las plantas (Voglmayr et al., 2014)

Este microorganismo causa deshidratación en los frutos en desarrollo, con malformaciones severas, ausencia de brillo y detenimiento del proceso de maduración (Hincapié Echeverri et al., 2017). El impacto es considerable, ya que genera pérdidas de producción entre el 50\% y 70\% (Rodríguez Díaz et al., 2017). Adicionalmente, el uso regular de fungicidas contribuye al desarrollo de cepas resistentes y de difícil control (Hukkanen et al., 2006).

Si bien la producción de $R$. glaucus Benth en Colombia ha mostrado una tendencia al aumento, la incidencia de Peronospora sp. es recurrente en los cultivos de los departamentos de Antioquia, Caldas, Risaralda, Santander, Cauca y Cundinamarca (Tamayo, 2001). Estudios realizados en ese país mencionan varias especies de Peronospora con incidencia en el cultivo de mora de castilla. Según Tamayo (2001), Hincapié Echeverri et al., (2017) y el Manual del Cultivo de Mora de la Gobernación de Antioquia (2014), el agente causal del mildeo velloso en este cultivo es Peronospora corda; Forero de La Rotta (1983) sugiere como agente causal a Peronospora rubi. Mientras que otros documentos señalan la especie Peronospora sparsa (ICA, 2011; Montoya Marmolejo et al., 2003).

La presencia de agentes infecciosos en las plantas activa mecanismos de defensa físicos y químicos para contrarrestar el estrés causado (Alegría et al., 2016). En el modelo de interacción hospedero-patógeno, varios estudios han demostrado efectos como la activación de la vía fenólica, caracterizada por un aumento de la síntesis de compuestos fenólicos (Alegría et al., 2016; Labanca et al., 2017).

En el género Rubus sp. se ha evaluado el efecto de los factores bióticos en el contenido de compuestos bioactivos (Ramos Solano et al., 2014; Ramos Solano et al., 2015). En la especie Rubus fructosus se ha encontrado que los disacáridos aislados de Fusarium oxyporum L. promueven la actividad de la enzima fenilalanina amoniaco liasa en sus células a concentraciones nanomolares (Nita Lazar et al., 2004). En ese sentido, se infiere que, los cultivos de mora de castilla podrían estar respondiendo de manera similar ante la infección del hongo.

Debido al impacto que tiene el mildeo velloso en la producción colombiana y considerando que se desconoce la especie de Peronospora que ocasiona daños en el cultivo de mora de castilla en el departamento Risaralda, se realizó esta investigación con el propósito de establecer la identidad taxonómica de la especie Peronospora causante de la enfermedad conocida como mildeo velloso en frutos de mora de castilla (R. glaucus Benth), determinando su efecto en el contenido de fenoles totales en los frutos.

\section{MATERIALY MÉTODOS}

\section{Lugar y periodo de estudio}

El muestreo se realizó en los municipios de Santuario y Santa Rosa de Cabal, ambos del departamento de Risaralda, en la zona Andina Colombiana, considerando su diferenciada localización geográfica dentro del departamento (Tabla 1). La investigación se realizó entre febrero y mayo del año 2017, tiempo durante el cual se tomaron muestras de $R$. glaucus Benth del material sin espinas en dos sectores de cada municipio seleccionado.

\section{Muestreo}

Previa identificación de los síntomas de mildeo velloso característicos de Peronospora sp. (Figura 1), se realizó un diseño en bloques totalmente al azar, donde se tomaron muestras de tallos de $R$. glaucus Benth y material sin espinas afectados por este microorganismo, que exhibieran algunas de las particularidades de esta patología como la presencia de esporangióforos y esporangios en la superficie. Se muestrearon aproximadamente 10 tallos por cultivo, los cuales fueron trasladados al laboratorio para posteriores análisis sobre la identificación taxonómica.

Para la obtención de extractos, se emplearon frutos en estado de madurez 5 y 6 , de acuerdo a la clasificación establecida en la norma NTC 4106 (ICONTEC, 1997). Las muestras se colectaron a partir de frutos sanos y afectados por $P$. sparsa en el mismo estado de madurez, seleccionándolos al azar. Se tomaron por cultivo, aproximadamente $500 \mathrm{~g}$ de cada material vegetal a evaluar.

El material obtenido se depositó en bolsas de polietileno con cierres herméticos, las cuales fueron transportadas en neveras a una temperatura de $4{ }^{\circ} \mathrm{C}$ desde el lugar de muestreo hasta el laboratorio de Biodiversidad y Biotecnología, para el estudio genético; y al laboratorio de Oleoquímica, para la evaluación del contenido de fenoles totales. 


\section{Identificación microscópica de Peronospora sparsa}

Se tomaron porciones de tallos de mora, con signos de mildeo velloso, corroborados por microscopía óptica. Posteriormente, las muestras se secaron con $\mathrm{CO}_{2}$ en un desecador de punto crítico (Sandri-780A®, EE. UU.) por $40 \mathrm{~min}$, se colocaron en porta muestras de cobre y se recubrieron con oro en una ionizadora (Ion Sputter JFC1100, JEOL®, Japón) por 1 min. Finalmente, las preparaciones se observaron y fotografiaron en un microscopio electrónico de barrido marca FEI, modelo Quanta 250 (Thermo Fisher Scientific).

\section{Protocolo de extracción de ADN}

La extracción de ADN se realizó a partir de tejido de tallos de $R$. glaucus Benth que presentaban lesiones características de Peronospora sp. (Figura 1). Se utilizó el Kit comercial Dneasy Plant Mini y se siguieron las instrucciones del fabricante. Finalmente, el ADN se almacenó a - $20^{\circ} \mathrm{C}$ para posteriores análisis.

\section{Verificación y purificación de ADN}

La extracción de ADN genómico se verificó por medio de electroforesis en gel de agarosa al 1.5\%, usando TBE 1 $\mathrm{X}$ (Tris-Borato-EDTA) en presencia de colorante y utilizando como marcador de peso molecular HyperLadder IV (100 a 1000 pb). Después de verificar la presencia de ADN se realizó la purificación, siguiendo la metodología descrita por Castillo et al. (2007).

\section{Confirmación taxonómica de Peronospora sparsa por la Reacción en Cadena de la Polimerasa (PCR)}

Se realizó una amplificación por PCR utilizando iniciadores específicos PS3 (5' ATT TTG TGC TGG CTG GC 3') y PS1 (5' TGC CAC ACG ACC GAA GC 3') diseñados por Aegerter et al., (2002).

Tabla 1: Localización de los cultivos de R. glaucus Benth. Material sin espinas con presencia de Peronospora sp. muestreados en el Departamento de Risaralda, Colombia, 2017

\begin{tabular}{|c|c|c|c|}
\hline Municipio de Risaralda & Finca & Coordenadas de Localización & Altitud (msnm) \\
\hline \multirow{2}{*}{ Santa Rosa de Cabal } & Canoas & $\mathrm{N} 04^{\circ} 52^{\prime} 37.2^{\prime \prime} \mathrm{W} 075^{\circ} 32^{\prime} 31.1^{\prime \prime}$ & $2244 \pm 4$ \\
\hline & El Rubí & N $04^{\circ} 53^{\prime} 24.1^{\prime \prime} \mathrm{W} 075^{\circ} 33^{\prime} 44^{\prime \prime}$ & $2085 \pm 3$ \\
\hline \multirow{2}{*}{ Santuario } & La Teresita & $\mathrm{N} 05^{\circ} 07^{\prime} 25.2^{\prime \prime} \mathrm{W} 076^{\circ} 00^{\prime} 01.2^{\prime \prime}$ & $2114 \pm 3$ \\
\hline & Bella Vista & $\mathrm{N} 05^{\circ} 06^{\prime} 45.0^{\prime \prime} \mathrm{W} 075^{\circ} 59^{\prime} 54.9^{\prime \prime}$ & $2120 \pm 3$ \\
\hline
\end{tabular}

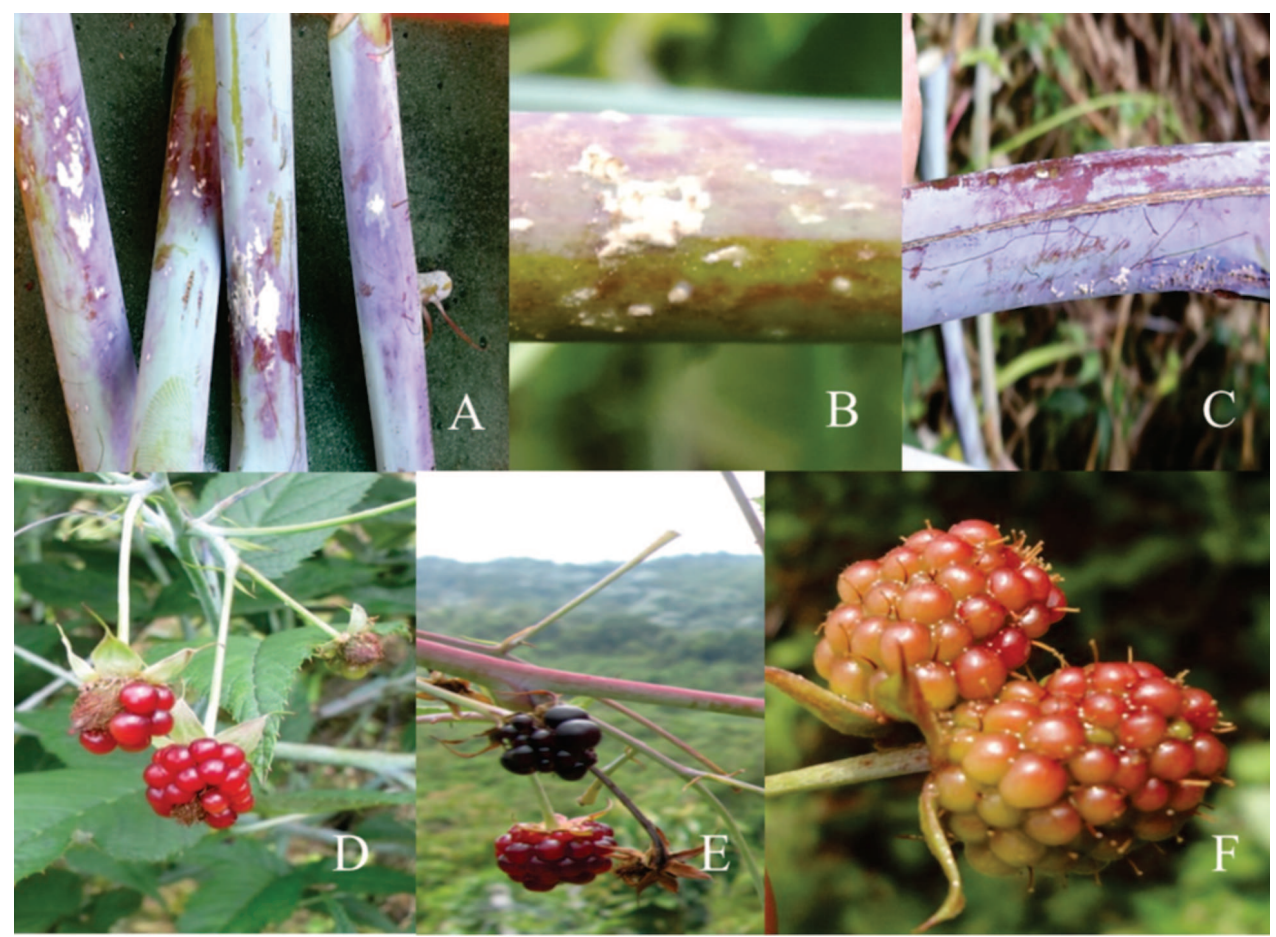

Figura 1: Síntomas de Peronospora sp. en R. glaucus Benth cultivados en Risaralda, Colombia. 2017. En tallo: A. Necrosis púrpurarojiza; B. Ampollas de color blanquecino donde se encuentra el microorganismo; C. Agrietamiento. En frutos: D. Malformación; E. Formación irregular de drupas; F. Frutos dobles. 
Las reacciones de PCR se llevaron a cabo en un volumen final de $12.5 \mu \mathrm{L}$, con $0.1 \mu \mathrm{M}$ de cada primer, $1 \mathrm{U}$ de Taq polimerasa, $0.2 \mathrm{mM}$ de cada dNTP, $1 \mathrm{X}$ de buffer de reacción (10 mM Tris- $\mathrm{HCl}, 50 \mathrm{mM}$ de $\mathrm{KCl}, 1.5 \mathrm{mM} \mathrm{MgCl}_{2}$ ), $2 \mathrm{mM} \mathrm{MgCl}$ y $10 \mathrm{ng} \mu \mathrm{L}^{-1}$ de ADN. El perfil de amplificación fue de tipo touch down. Se inició con una desnaturalización a $95{ }^{\circ} \mathrm{C}$ por 3 minutos; seguido de 10 ciclos a $95^{\circ} \mathrm{C}$ por 2 minutos; un proceso de apareamiento con disminución de temperatura de $0.5^{\circ} \mathrm{C}$ por cada ciclo $\left(62^{\circ} \mathrm{C}\right.$ hasta $\left.57^{\circ} \mathrm{C}\right)$ por 1 minuto y 18 segundos y $72{ }^{\circ} \mathrm{C}$ por 2.30 minutos. El proceso de elongación establecido fue de 35 ciclos de 95 ${ }^{\circ} \mathrm{C}$ por 2 minutos, $60{ }^{\circ} \mathrm{C}$ por 1.18 minutos y $72{ }^{\circ} \mathrm{C}$ por 2.30 minutos; y una extensión final a $72{ }^{\circ} \mathrm{C}$ por 10 minutos. La visualización de los productos amplificados de PCR se realizó en gel de agarosa al 1.8\% usando el marcador de peso molecular HyperLadder IV.

\section{Obtención de extractos polares de frutos maduros de R. glaucus Benth a partir de materiales sin espina sanos y afectados por Peronospora sparsa}

Para la obtención de los extractos, se procesaron aproximadamente $3 \mathrm{~g}$ de frutos en un molino operado por corte e impacto. La extracción se llevó a cabo por hidrólisis ácida, empleando etanol al $80 \%$ y ajustando el pH a 2.6 con adición de ácido cítrico, tal como lo indica Guzmán Nieves (2011). Se usó una relación muestra-solvente de 1:8 con agitación mecánica orbital a $250 \mathrm{rpm}$ por 2 horas a temperatura ambiente(Abu Bakar et al., 2016; Li et al., 2010; Veliæanski et al., 2012).

\section{Evaluación del contenido de fenoles totales}

Se empleó el método de Folin-Ciocalteu, según modificaciones realizadas a la metodología descrita por Magalhães et al., (2010). Se utilizó un espectrofotómetro para microplacas, donde se mezclaron $50 \mu \mathrm{L}$ del extracto (previamente diluido FD: 50), $120 \mu \mathrm{L}$ de agua, $50 \mu \mathrm{L}$ del reactivo de Folin-Ciocalteu (1:20) y $80 \mu \mathrm{L}$ de $\mathrm{KOH}(0.175$ M), la medición de la absorbancia se realizó a 760 nm y se empleó una curva de calibración utilizando ácido gálico como estándar de referencia, en un rango de concentraciones de 5 - $80 \mathrm{mg} \mathrm{L}^{-1}$. Los resultados se expresaron como miligramo de equivalentes de ácido gálico por gramo de muestra (mg AGE g-1 muestra).

\section{Análisis estadístico}

Los promedios y desviaciones estándar se obtuvieron a partir de tres repeticiones de cada una de las muestras evaluadas. Se realizó un análisis de varianza ANOVA mediante el software IBM SPSS Statistics Versión 22 y la confirmación con la prueba de Tukey para establecer diferencias y/o similitudes en cuanto al contenido de compuestos fenólicos en las diferentes zonas de estudio.

\section{RESULTADOS}

\section{Síntomas causados por mildeo velloso (Peronospora sp.)}

Se observaron los síntomas del daño causado por Peronospora sp. en frutos y tallos de los cultivos de mora de castilla evaluados, como se muestra en la Figura 1.

En el tallo se observó una coloración roja-púrpura atribuido a un proceso de necrosamiento del tejido y en frutos, malformación e inhibición del proceso de madurez.

Posteriormente, se realizó una observación microscópica de los tallos esporulados. Los resultados obtenidos se muestran en la Figura 2.

\section{Verificación de la especie por PCR y evaluación del contenido de fenoles totales}

La amplificación por PCR confirmó la presencia de una banda entre 660 a 700 pb, correspondientes a las muestras positivas afectadas por $P$. sparsa. De las muestras analizadas, los municipios de Santuario y Santa Rosa de Cabal mostraron la mencionada banda, como se muestra en la Figura 3.

Los resultados obtenidos para el contenido de fenoles totales evaluados por el método de Folin Ciocalteu de cada uno de los extractos, se presentan en la tabla 2. Según el análisis de varianza, se encontraron diferencias significativas entre los extractos obtenidos a partir de los diferentes tipos de material vegetal ( $\mathrm{p}<$ 0.05), es decir, frutos sanos y afectados por Peronospora sp, lo cual se confirmó con la prueba de Tukey. Sin embargo, no existieron diferencias significativas del contenido de fenoles totales entre los municipios evaluados.

\section{DISCUSIÓN}

Los síntomas más relevantes de $P$. sparsa que se manifestaron en $R$. glaucus Benth identificados en este estudio fueron la presencia de manchas púrpuras a lo largo del tallo, indicador de una infección sistémica (Álvarez Romero et al., 2013) y en los frutos, pérdida de brillo, llenado irregular de las drupas, frutos dobles o partidos, con huecos en la parte central y un retraso o inhibición en el proceso de maduración, como se observa en la figura 1. Los resultados obtenidos coinciden con la información reportada por otros autores para Rubus sp. (Rodríguez et al., 2017), Rubus fruticosus (Rebollar Alviter, 2011) y Rubus arcticus (Kostamo et al., 2015).

Se logró identificar algunas de las características morfológicas para el género Peronospora sp. descritas por Álvarez Romero et al., (2013), donde se observó esporangios y esporangióforos con ramificaciones dicotómicas (Figura 2). 
En este estudio se confirmó la identidad taxonómica de la especie $P$. sparsa como el agente causal del mildeo velloso de la mora de castilla ( $R$. glaucus Benth), en el departamento de Risaralda, Colombia, mediante la prueba molecular basada en el criterio de amplificación con iniciadores específicos PS1 y PS3, como se observa en la figura 3. El peso molecular de los productos amplificados en la PCR se encontró alrededor de 660 - 700 pb, lo que coincide con los resultados reportados por Aegerter et al., (2002), Álvarez Romero et al., (2013) y Ayala Vásquez et al., (2008).

El rango de contenido de fenoles totales para los extractos obtenidos a partir de frutos maduros de $R$. glaucus Benth sanos fue de 7.75 a 10.08 mg AGE g ${ }^{-1}$ muestra, mientras que para el extracto obtenido a partir de frutos afectados por $P$. sparsa fue de 9.38 a $14.7 \mathrm{mg}$ AGE $\mathrm{g}^{-1}$ muestra, siendo evidente una mayor concentración de estos compuestos en los extractos afectados (Tabla 2).

Los resultados coincidieron con los reportes sobre acumulación de compuestos fenólicos como una respuesta al estrés de las plantas causada por un cambio en la actividad de la fenilalanina amonioliasa, enzima clave en la ruta metabólica fenilpropanoide (Alegria et al., 2016). Se evidenció que en los cultivos sanos de la especie $R$. glaucus Benth estos compuestos se encuentran a nive-

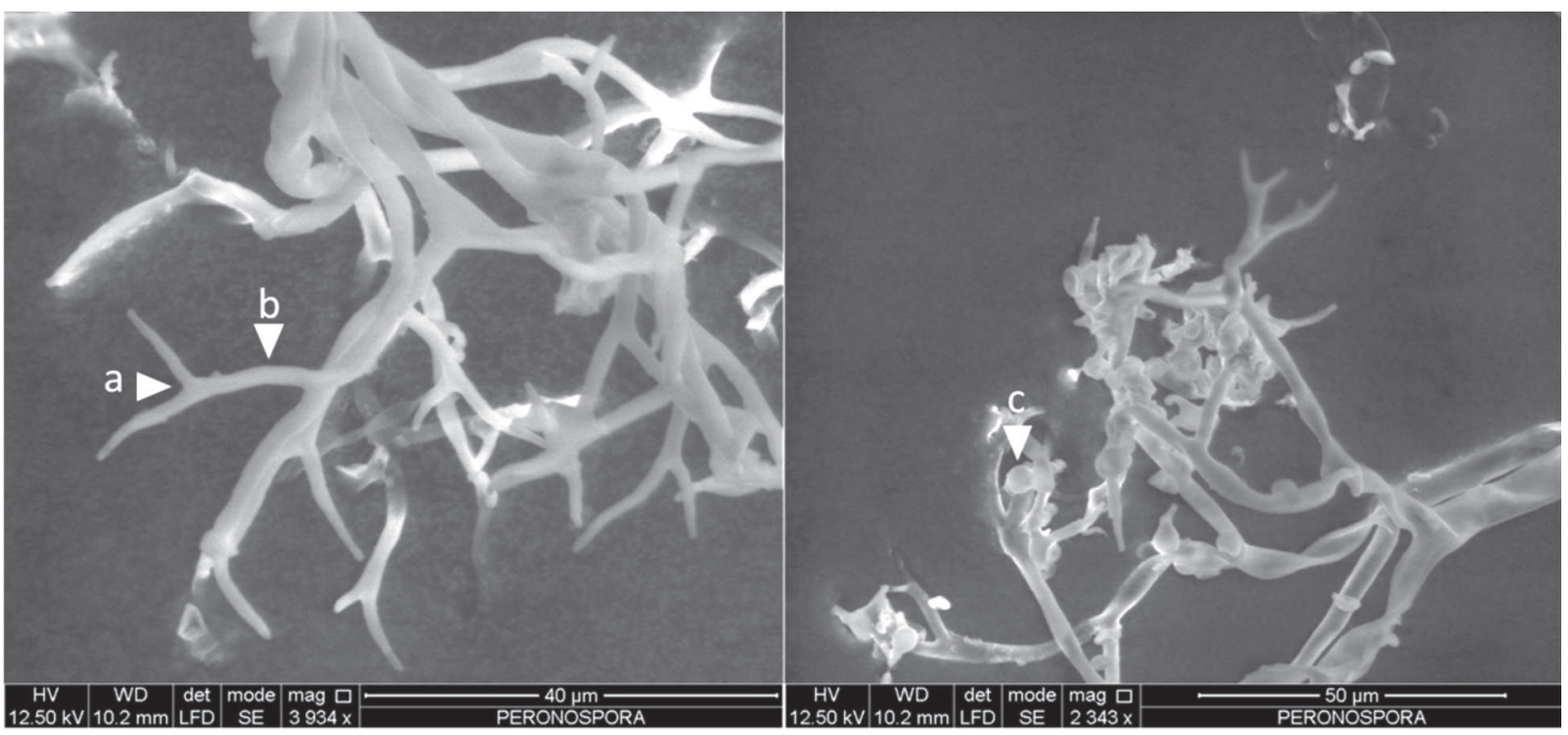

Figura 2: Observación por microscopia electrónica de barrido de Peronospora sp., encontrado en tallos esporulados de $R$. glaucus Benth sin espina cultivada en Risaralda, Colombia. 2017. a. ramificaciones dicotómicas, b. esporangióforos y c. esporangios.

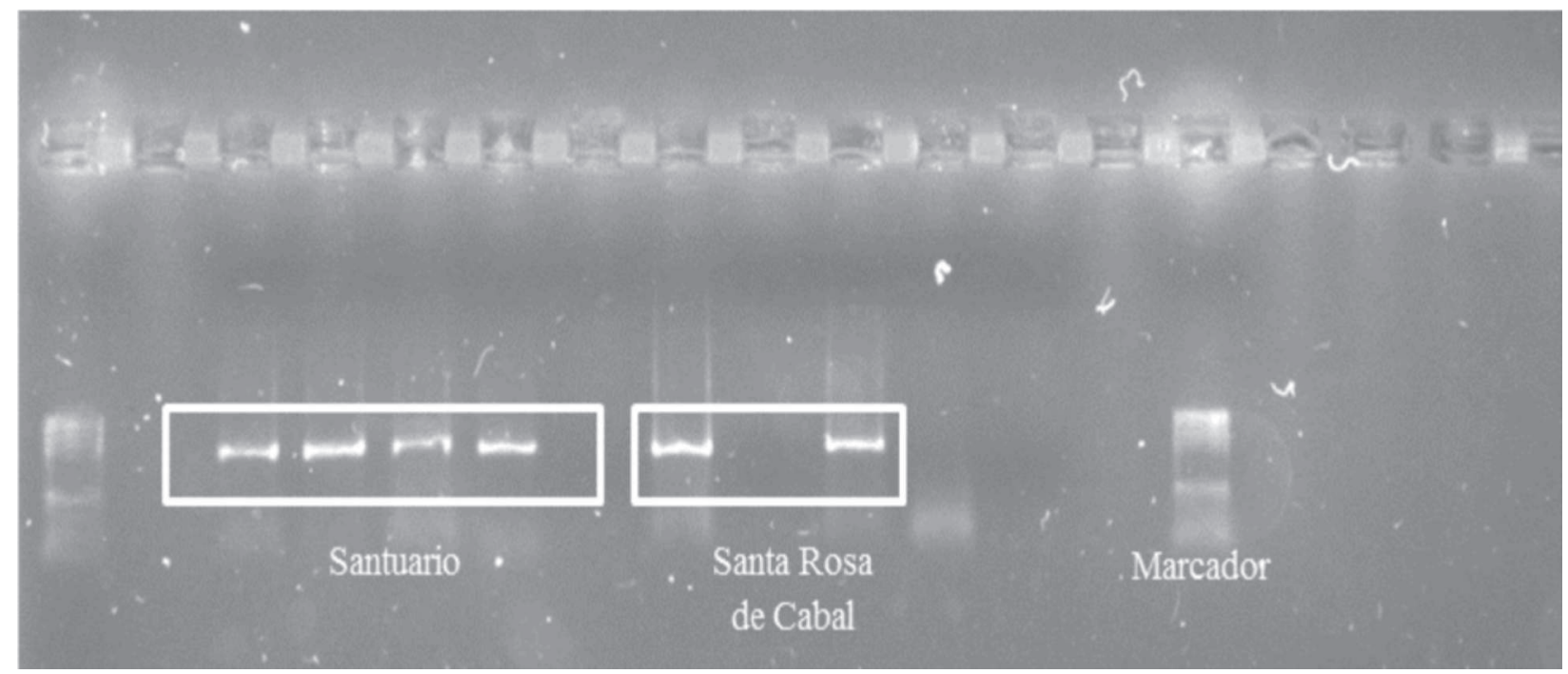

Figura 3: Productos de amplificación de la PCR obtenidos con los cebadores PS1 y PS3, para la identificación taxonómica de Peronospora sparsa encontrada en $R$. glaucus Benth sin espina cultivada en dos municipios de Risaralda, Colombia. 2017. 
Tabla 2: Contenido de fenoles totales de los extractos obtenidos a partir de frutos de $R$. glaucus Benth sanos, material sin espina y afectados por $P$. sparsa cultivados en Risaralda, Colombia. $2017^{(1)}$

\begin{tabular}{lccc}
\hline \multirow{2}{*}{$\begin{array}{l}\text { Municipio } \\
\text { Lugares de muestreo }\end{array}$} & \multicolumn{2}{c}{ Contenido de Fenoles Totales (mg AGE $\mathbf{~}^{-\mathbf{1}}$ muestra) } \\
\cline { 3 - 4 } Santuario & Bella Vista & Fruto Sano Maduro (FSM) $^{\text {a }}$ & Fruto Enfermo Maduro (FEM) $^{\mathbf{b}}$ \\
\cline { 2 - 4 } & La Teresita & $10.08 \pm 0.38$ & $14.70 \pm 1.11$ \\
\hline \multirow{2}{*}{ Santa Rosa de Cabal } & El Rubí & $9.52 \pm 1.42$ & $13.71 \pm 0.43$ \\
\cline { 2 - 4 } & Canoas & $7.75 \pm 0.18$ & $11.51 \pm 1.05$ \\
\hline
\end{tabular}

(1) Los promedios con letra común no son significativamente diferentes a través de la prueba de Tukey ( $\mathrm{p} \geq 0.05$ )

les más bajos que en los infectados, razón por la cual es posible afirmar, que la diferencia se debió a un mecanismo de defensa de las plantas y que su concentración aumentó con el fin de contrarrestar la invasión de los patógenos, tal como indican otros autores (Alegría et al., 2016; Paredes López et al., 2010).

\section{CONCLUSIONES}

Los resultados de este estudio confirmaron la identidad taxonómica de Peronospora sparsa como la especie causal de mildeo velloso en mora de castilla cultivada en el departamento de Risaralda, Colombia.

Además, se pudo establecer que la presencia de este microorganismo produjo un incremento significativo en el contenido de compuestos fenólicos de los frutos.

\section{AGRADECIMIENTOS}

A la Universidad Tecnológica de Pereira y al programa de investigación "Desarrollo de capacidades científicas y tecnológicas en biotecnología aplicada a los sectores de salud y agroindustria en el departamento de Risaralda" del Sistema General de Regalías (BPIN 2012000100050) por la financiación de este proyecto.

\section{REFERENCIAS}

Abu Bakar MF, Ismail NA, Isha A \& Mei Ling AL (2016) Phytochemical composition and biological activities of selected wild berries (Rubus moluccanus L., R. fraxinifolius Poir., and R. alpestris Blume). Evidence-Based Complementary and Alternative Medicine, 2016:01-10.

Aegerter BJ, Nuñez JJ \& Davis RM (2002) Detection and management of downy mildew in rose rootstock. Plant Disease, 86:1363-1368.

Alegria C, Gonçalves EM, Moldão Martins M, Cisneros Zevallos L \& Abreu M (2016) Peel removal improves quality without antioxidant loss, through wound-induced phenolic biosynthesis in shredded carrot. Postharvest Biology and Technology, 120:232-239.

Álvarez Romero PI, García Velasco R, Mora Herrera ME, González Díaz JG \& Salgado Siclán ML (2013) Estado actual de Peronospora sparsa, causante del mildiu velloso en rosa (Rosa sp.). Revista Mexicana de Fitopatología, 31:113-125.
Ayala Vásquez M, Argel Roldan LE, Jaramillo S \& Marín Montoya M (2008) Diversidad genética de Peronospora sparsa (Peronosporaceae) en cultivos de rosa de Colombia. Acta Biológica Colombiana, 13:79-94.

Castillo N, Reed BM \& Bassil NV (2007) Fingerprinting and genetic stability of Rubus using molecular markers. HortScience, 42:914.

Forero de La Rotta MC (1983) Reconocimiento de las enfermedades de la mora de castilla (Rubus glaucus Benth) en el Municipio de Venecia (Cundinamarca). Bogotá, Instituto Colombiano Agropecuario. 20p.

Gobernación de Antioquia (2014) Manual técnico del cultivo de mora bajo buenas prácticas agrícolas. Secretariìa de Agricultura y Desarrollo Rural, Medellín. 113p.

Guzmán Nieves CA (2011) Proceso de obtención de un extracto de compuestos fenólicos a partir de orujo de uva tinta Vitis vinifera a bajas temperaturas para aplicación en alimentos y bebidas destinados a consumo humano y animal. Patente WO 2011/062468 A2, México. 16p.

Hincapié Echeverri OD, Saldarriaga Cardona A \& Díaz Díez C (2017) Biological, botanical and chemical alternatives for the control of blackberry (Rubus glaucus Benth.) diseases. Revista Facultad Nacional de Agronomía Medellín, 70:81698176 .

Hukkanen A, Pietikäinen L, Kärenlampi S \& Kokko H (2006) Quantification of downy mildew (Peronospora sparsa) in Rubus species using real-time PCR. European Journal of Plant Pathology, 116:225-235.

Ica (2011) Manejo fitosanitario del cultivo de la mora (Rubus glaucus Benth): Medidas para la temporada invernal. Bogotá, Produmedios. 32p.

Icontec (1997) Frutas Frescas. Colombia, Instituto Colombiano de Normas Técnicas y de Certificación. 15 p. (Norma Técnica Colombiana, 4106).

Kostamo K, Toljamo A, Palonen P, Valkonen JPT, Kärenlampi SO \& Kokko H (2015) Control of downy mildew (Peronospora sparsa) in arctic bramble (Rubus arcticus ssp. arcticus). Annals of Applied Biology, 167:90-101.

Labanca R, Barbosa De Oliveira G \& Alminger M (2017) Berries: Cultivation and environmental factors effects on the phenolic compounds content. African Journal of Agricultural Research, 12:1602-1606.

Li W, Qiu Y, Patterson CA \& Beta T (2010) The analysis of phenolic constituents in glabrous canaryseed groats. Food Chemistry, 127:10-20.

Magalhães LM, Santos F, Segundo MA, Reis S \& Lima JL (2010) Rapid microplate high-throughput methodology for assessment of Folin-Ciocalteu reducing capacity. Talanta, 83:441-447. 
Montoya Marmolejo CA, Hincapié LA \& Uribe Flórez V (2003) Principales enfermedades y plagas en el cultivo de la mora. Bogotá, Instituto Colombiano Agropecuario. 20p.

Nita Lazar M, Heyraud A, Gey C, Braccini I \& Lienart Y (2004) Novel oligosaccharides isolated from Fusarium oxysporum L. rapidly induce PAL activity in Rubus cells. Acta Biochimica Polonica, 51:625-634.

Paredes López O, Cervantes Ceja ML, Vigna Pérez M \& Hernández Pérez T (2010) Berries: Improving Human Health and Healthy Aging and Promoting Quality Life-A Review. Plant Foods for Human Nutrition, 65:299-308.

Ramos Solano B, Garcia Villaraco A, Gutierrez Mañero FJ, Lucas JA, Bonilla A \& Garcia Seco D (2014) Annual changes in bioactive contents and production in field-grown blackberry after inoculation with Pseudomonas fluorescens. Plant Physiology and Biochemistry, 74:01-08.

Ramos Solano B, Algar E, Gutiérrez Mañero FJ, Bonilla A, Lucas JA \& García Seco D (2015) Bacterial bioeffectors delay postharvest fungal growth and modify total phenolics, flavonoids and anthocyanins in blackberries. Food Science and Technology, 06:437-443.
Rebollar Alviter A (2011) Manejo del mildiu y el moho gris de la Zarzamora en Michoacán. Primera edición. Universidad Autónoma Chapingo, México. 35p.

Rodríguez Díaz KJ, Silva Rojas HV, Boyzo Marín J, Segura Ledesma SD, Leyva Mir SG \& Rebollar Alviter A (2017) Molecular detection of Peronospora sparsa in sources of primary inoculum and components of resistance in wild blackberry species. European Journal of Plant Pathology, 149:845-851.

Tamayo PJ (2001) Principales enfermedades del tomate de árbol, la mora y el lulo en Colombia. Medellín, Centro de Investigación La Selva. 40p. (Boletín Técnico 12).

Veliæanski AS, Cvetkoviæ DD \& Markov SL (2012) Screening of antibacterial activity of raspberry (Rubus idaeus L.) fruit and pomace extracts. Acta Periodica Technologica, 43:305-313.

Voglmayr H, Montes-Borrego M \& Landa BB (2014) Disentangling Peronospora on Papaver: phylogenetics, taxonomy, nomenclature and host range of downy mildew of opium poppy (Papaver somniferum) and related species. Plosos One, 09:0117. 